\title{
An Overview of the Challenges and Opportunities for Globalization of Nigeria Libraries By
}

\author{
S.E. ODEH AND A. C. OKOLI (MRS)
}

\begin{abstract}
The paper is an overview of the existing challenges and opportunities of globalization of Nigerian libraries. It examine the challenges and opportunities for the establishment of viable information and communication Technologies (ICTs) and recommends the way forward for interconnectivity of Nigerian libraries to facilitate resource sharing and exchange of information.
\end{abstract}

\section{Introduction}

The advent of computer and indeed the internet in the 20th century have aided communication tremendously.' This invariably has socio-cultural, political and economic implications on Nigerian universities. Computers and the internet have globalised the practice of librarianship worldwide. This globalization has endeavored libraries around the world to cooperate and collaborate through inter-library loan system and formation of library consortia, which are alliances formed by member libraries on voluntary basis to facilitate resource sharing in pursuit of common interest (Aina,2003).

The concept of globalization as a term that is often used to refer to economic globalization; that is integration of national economic into international economy through trade, foreign direct investment, capital flows, migration, and speed of technology. (Akanni, 2008). It is often argued that globalization could also be defined as internationalism; however, this concept is misleading as "global" implies one world as single unit, whereas, "international" which implies between nations recognizes that different peoples, cultures, languages, nations, borders, economic and eco-system exist. These definitions enable the writers to examine the challenges and opportunities of globalization to Nigerian libraries.

\section{Globalization and the Information Age}

In the year 2000 the media were full of references to globalization of economy and communications and even politics, education and military affairs. Globalization can then be described as a phenomenon involving the integration of economies, culture, governmental policies, political movements and even education. What is now called globalization however represent an exponential acceleration of the integration process.
As early as 1962 the Canadian University Visionary, Marshall Mcluhan wrote that the electronic age was turning all humanity into a "global tribe" and the term global village is attributed to him. The British Broadcasting Corporation (BBC), Cable News Network (CNN), Music Television (MTV) and the Internet have accelerated the integration of global culture. With globalization this world as a whole also becomes a social space in its own right. The new information and communication technologies range from e-mail to cellular telephone to tele-conferencing. Let more people share knowledge without having to be in the same place. Through globalization people become more able, physically, legally, culturally and psychologically to engage with each other in "one world". Global communications takes many forms. For example, jet aeroplanes transport passengers and cargoes across any distance on the planet within a day.

Telephones and computer networks affect near instantaneous interpersonal communication between points all over the earth. Electronic mass media broadcasts messages to the world audiences. Globalization is the trend whereby these various kinds of global relations emerge proliferate and expand.

\section{Nigerian Libraries and Globalization}

The University libraries have long been recognized as the "heart" of their universities. To fulfil their mission of supporting the educational objectives, of their present bodies which include teaching, learning, research and cultural development as the case may be, the libraries had to develop and maintain books, journals and audio visual collections and services. During the "oil boom" era the libraries flourished. They were busy filling their shelves with learning materials in order to sustain academic disciplines established by their parent organizations. Today the story is different. Nigerian libraries have 
problems even in maintaining core collections and activities because of the lack of money and high inflation, coupled with this is the emergence of ICTs in the educational system world wide. As revealed by Agulu (1996) since the onset of the current recession the government have been giving grants that are not commensurate with the rapid growth in the number of libraries in Nigeria. The resultant under funding in libraries has become perennial and may remain so if the national economy does not improve significantly. It must be pointed out that Nigerian libraries have not been isolated from the financial problems of their parent bodies.

By the second half of the 19th century, Western countries had experienced such a proliferation of books of all sorts that the nature of the libraries work radically altered and being well read no longer covered a sufficient characteristics of the past. The librarian needed some means of easy and rapid identification as well as strong organization and administrative skills and the necessity for specialized training soon become clear. The library of today should no longer be a library of the $17^{\text {th }}$ century image. The pace of change brought by new technologies has had a significant effect on the way people live, work and play world wide. New and emerging technologies challenge the traditional process of teaching and learning and the way education is managed. Many higher educational institutions have also exploited the potentials of new information and communication technologies to develop new approaches to distance education, especially in business and management of computing. These new forms of globalization are beginning to replace more conventional type of academic exchange among the world libraries.

Although traditional channels of communication will remain important, the new information and communication technologies hold great potentials for broadly disseminating knowledge at low cost and for reducing knowledge gap within countries and between industrial and developing countries. In a broad sense, access to the right information at the right time gives people greater control over their destinies. As a result of all these global changes the purpose of higher education have been transformed. As revealed by Capion (2000), mail, telephone, TV and radio,' books, newspapers and periodicals are the traditional way users send and receive information. However, data communication system - computer system that transmit data over cable have been evolving since the mid - 1980s. The use of intemet has revolutionized access to information for the business world, libraries, education and individuals. A few of the most popular include e-mail and world wide web. All these technological devices can be regarded as backbone of the concept of globalization. The internet and its technology continues to have a profound effect on promoting the sharing of information especially in the academic, making possible rapid transactions among business and supporting global liberalization among individuals and organizations.

These technologies have the potential to develop virtual libraries and this increase users access and participation. According to Daniel (2000) Nancy Schillis was one of the first writers to use the expression "virtual. library" which she designed in 1992, simply as libraries in which computer and telecommunication technologies make access to a wide range of information resources possible. Today this same concept is referred to variously as "digital library" "electronic library" "community network" or simply as "library without walls". It is called "virtual" because in a good electronic wide area networked library, the user enjoys the euphois of being in the distant libraries and yet has not physically moved. It is an experience of virtual reality. One of its features is that its emphasis is access over ownership of collections. This stems from assumption that the whole universe of the global information superhighway is a human resource and heritage which all who have the necessary infrastructure capabilities can tap for their own development. The virtual library is a child of necessity arising from the need to use technologies in accessing the worlds information overload, or information explosion for human survival and development. The need for a virtual library system has therefore become a most urgent necessity in the Nigerian libraries. World wide web resources are recognized in such a way that users can easily move from one resource to another. Using it, readers can absorb some information and take less time to do so. Librarians can now easily find out any information concerning any

book within a couple of minutes. Thanks to the concept of globalization. It must be realized that information science is indispensable to the progress of librarians and it compasses that set of research necessary to suggest the profession now being called librarianship. 


\section{Challenges of Globalization}

Nigerian libraries are faced with several challenges of globalization. Sewell (1998) enumerated four major challenges that globalization posses to government, civil society, and other policy makers. These include, the problem of extending globalization to all countries; the fear that globalization would lead libraries into instability; the fear that global competition would cause reduction in wages, labour rights, employment

practices and environment; and the fear of using the complications resulting from globalization as excuse to avoid making new efforts. The implication of the above problems on globalization of Nigerian libraries can therefore be discussed in relation to conformity with global standards in the application of computer in libraries as well as the development of electronic libraries, most especially, virtual library system.

Conformity of Global Standards in the Application of Computers in Libraries Obilade (2003) has stressed that Nigeria libraries have to cope with global standards in library organization. In order words, the libraries should be able to apply information communication technologies (ICTs), provision of current awareness services using Selective Dissemination of Information (SDI), access of users to libraries through electronic access cards and regular survey of users, preferably through electronic access cards to obtain statistics of library users. Furthermore, it has now become imperative that the present minimum global standards must be complied with as a major criteria and requirement for course accreditation in all institution that offer degree programmes in library science in Nigeria. This is in conformity with the Nigerian Library Association Decree of 1995, which insists that the Librarian Registration Council of Nigeria (LRCN) must take cognizance of the existence of electronic libraries.

\section{Development of Electronic Libraries (Virtual Library System)}

Akanni (2008) posits that one sure way of responding to the challenge of globalization is the provision of virtual library services. Because of cost implications this option may not be feasible. However, the two ways by which this can be achieved are for group libraries to combine their efforts and resources to form a consortium; and provision of facilities to access various virtual libraries within and outside Nigeria. This therefore means that ICTs is at the forefront of Nigerian libraries. Unfortunately, ICT are yet

to be properly developed in Nigeria. ICT has its attendant problems of high costs of gadgets, planning and implementation, and ICT experts to man the electronic and virtual libraries.

\section{Opportunities to Nigerian Libraries}

The opportunities that exists in the globalization of Nigerian libraries may be summed up as providing for online 'access to a library catalogue; ability to access more information via the online search services than would have been possible via printed sources; and the ability to produce easily, management information such as cost of new books, and numbers of books on loan to specific groups (Tedd, 1984). However, Akanni (2008), discussed the benefits of globalization in Nigerian libraries along improved access to information; enhanced educational development; improvement in the status of Nigerian libraries; digitization of local contents; improved collection development and conservation of space.

\section{The Way Forward}

Considering the myriad challenges that are associated with the implementation of a viable globalization of libraries, it is imperative that the authors make some recommendations for successful of Nigeria libraries. Not withstanding the country's economic position in the face of the present global economic meltdown, Nigerian libraries can reap the benefits of globalization if they are equipped to what facilitate resource sharing and exchange of information within and outside the country through the internet. This can work perfectly if a consortium of stakeholders is established towards the formation of National information Network by the government. Aid may be sourced from national and international organizations for this purpose.

\section{Conclusion}

The challenges and opportunities for the globalization of Nigerian libraries are many. Particularly important in this is the need to conform to global standards in the application of computer in libraries. Among other things, the libraries should be able to apply information 
communication Technologies (ICTs). The benefits of globalization includes among other things, the ability to access more information via the on-line search services. Despite the challenges, the prospects for globalization of Nigerian libraries look bright.

\section{REFERENCE}

Akanni, S.B. (2008) Globalization: Challenges and Opportunities for Nigerian Libraries, Proceedings of 46th annual National conference of Nigerian Library Association Kaduna.

Aniogbolu C. Ejitasha (2008). International Journal of Economic and Development Issues V 01. 7 No. 1 p. 198.

Capron H. L. (2000) Computers: Tools for an information Age. New Jersey: Prentice Hall.
Daniel J. O. (2000) Virtual Library for Nigerian Libraries 36(2)56.

Ogunsita L.A (2004) Electronic Journal of Academic and Special Librarianship Vol. 5 Nos. 2 - 3.

Nko R. A. (1984) Application of Modem Technology in the Library Nigerian Library and Information Science Review 2 (182) 5.

Olatoyegun V. I. (2005) Globalization and Inequality of bargaining: International Journal of Economic Development Issues. Development Universal Consortia V 01. $5(182) 6$.

Scholtic J. H. (2000) Globalization in Microsoft Encarta Encyclopedia. Redmond W. A. Microsoft.

John W. Sewell (1998) Challenges of Globalization: Toward a 